\title{
Factors associated with neonatal near miss and death in public referral maternity hospitals
}

Ocília Maria Costa Carvalho 1

(D) https://orcid.org/0000-0003-2522-007X

Antônio Brazil Viana Junior 2

https://orcid.org/0000-0001-6608-3134

Matheus Costa Carvalho Augusto 3

https://orcid.org/0000-0001-9336-4265

Ana Tallita Oliveira Xavier 4

https://orcid.org/0000-0002-7039-0716

\author{
Ana Paula Mendes Gouveia 5 \\ (iD) https://orcid.org/0000-0002-7240-9257 \\ Fernanda Nogueira Barbosa Lopes 6 \\ (iD) https://orcid.org/0000-0001-8711-6599 \\ Francisco Herlânio Costa Carvalho 7 \\ iD https://orcid.org/0000-0002-6400-4479
}

\footnotetext{
1-7 Departamento de Saúde Comunitária. Universidade Federal do Ceará. Rua Prof. Costa Mendes, 1608. 5 andar. Rodolfo Teófilo. Fortaleza, CE, Brasil. CEP: 60.430-140. E-mail: ociliacarvalho@hotmail.com
}

\begin{abstract}
Objectives: to evaluate factors associated with neonatal near miss and death in reference hospitals.

Methods: this case-control study included 364 cases and 728 controls among 4,929 births. Cases were identified by Apgar $<7$ at 5 minutes, weight $<1500$ g, gestational age $<32$ weeks, mechanical ventilation or congenital malformation. After follow-up, outcomes were reclassified into: true controls, near miss and neonatal death. Hierarchically, variables with a p-value $\leq 0.20$ were included in the multiple logistic regression.

Results: the neonatal near miss rate was 54.1 per 1,000 live births, and the near-miss-todeath ratio was 2.75. Between the control and near miss groups, the predictor variables were neonatal intensive care admission $[O R=35.6$ (16.7 - 75.9)] and central venous access $[O R=74.8(29.4-190.4)]$. Between the control and death groups, neonatal intensive care admission $[O R=100.4(18.8-537.0)]$ and central venous access $[O R=12.7(3.7-43.2)]$ were significant. Between the near miss and death groups, only Apgar $<7$ at 5 minutes [OR $=4.1(1.6-10.6)]$ and vasoactive drug use $[O R=42.2(17.1-104.5)]$ were significant .

Conclusion: factors associated with a greater chance of near miss and/or neonatal death were: Apgar score $<7$ at 5 minutes, neonatal intensive care confinement, having central venous access, and use of vasoactive drugs.
\end{abstract}

Key words Near miss, Child mortality, Infant low birth weight

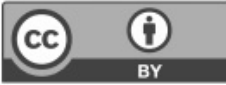




\section{Introduction}

A neonatal near miss (NNM) is generally used to describe a newborn who survives a life-threatening condition during the first 28 days of life. $1^{1}$ However, the absence of a universally accepted standard definition is still considered a challenge to identify and estimate its actual magnitude.2,3

Among the 5.6 million children who died before their fifth birthday in 2016, approximately $46 \%$ (2.6 million) perished in the first month of life. If this trend continues, 30 million of the 60 million children estimated to die between 2017 and 2030 will occur during the neonatal period. It is unacceptable for the scientific community that 7,000 of the 15,000 children dying every day have died in the neonatal period.4 In Brazil, despite the decline in infant mortality, 42,049 and 25,555 child deaths were recorded in 2017 before the fifth year of life and in the neonatal period, respectively. 5

The prevalence of NNM is four to six times higher than the mortality rate, 3,6 which demonstrates its probable effectiveness as an instrument for estimating the chance of survival in children with perinatal conditions and potentially fatal complications.

Even when they survive these conditions, they are more prone to morbidities during the first years of life, and more likely to become carriers of chronic conditions even in childhood.7,8 Understanding complex and high-risk conditions provides relevant information for appropriate guidance, which contributes to the prevention of undesirable outcomes.

With the consistently high incidence in the recent decades, it is understood that the concept of morbidity is equally relevant and worrisome in the current global health scenario. Thus, the collection of quantitative and qualitative data related to severe morbidity, through the neonatal near miss criteria, is crucial to combat the increasing neonatal mortality.

So far, few studies have searched for criteria that reflect risk conditions at birth, through which we define near miss classification factors. Among these studies, the paper of Silva et al. ${ }^{3}$ stood out for its applicability. In their study, they have defined the following neonatal risk-associated key elements: Apgar score, birth weight, gestational age, use of mechanical ventilation (MV), and presence of congenital malformation. However, other associated factors (maternal, gestational, and perinatal) must also be evaluated in different settings (geographic locations and health care conditions) to better understand how these contribute to neonatal near miss or death.
Here, we aimed to evaluate the factors associated with near miss morbidity and neonatal death in a public maternity hospital in the state of Ceará, a region still marked by high rates of neonatal and maternal morbidity and mortality.

\section{Methods}

A case-control study was carried out involving all the live births of the Maternity School Assis Chateaubriand (Federal University of Ceará) from January to December 2017. Cases were defined as having at least one of the neonatal near miss criteria by Silva et al. ${ }^{3}$ : (1) Apgar score $<7$ in the $5^{\text {th }}$ minute, (2) birth weight $<1500 \mathrm{~g}$, (3) gestational age $<32$ weeks, (4) use of mechanical ventilation, or (5) presence of congenital malformation.

For the controls, it wasselected a newborn who did not present with any of these pre-established severity criteria, with a sequence of birth immediately before the case, and a newborn immediately after the identified case, in a proportion of $(2: 1)$. Prospective cases (1) whose information could not be obtained from medical records or by interview with family members, (2) that were abortions $(<20$ weeks and weight less than $500 \mathrm{~g}$ ), (3) with congenital malformations considered lethal or chromosomal syndromes, and (4) whose births occurred outside the hospital environment were excluded for the study. Prospective controls who had (1) and (2) were also excluded.

Cases $(27 \%$ of newborns) were transferred to two hospitals (a maternity hospital and a general hospital with neonatal support) within the state of Ceará. These newborns were followed up until hospital discharge or the 28th day of life (in any of the institutions). After follow-up, cases and controls were reclassified according to outcomes: true controls (survival to the neonatal period without having any of the near miss criteria), near miss and neonatal death.

Data included the standardized measurements using several instruments and information from the maternal and neonatal medical records such as Birth and Death Declaration and the pregnant woman's card.

To analyze the study variables, a hierarchical model was adapted from Lima et al. ${ }^{9}$ The variables classified into:

Block I - distal variables - sociodemographic variables - education, marital status, race, origin, occupation; Block II, III, IV and V - intermediate variables I and II - I. maternal characteristics and conditions - age, number of pregnancies, arterial 
hypertension, diabetes mellitus, smoking, anemia, urinary tract infection. II. characteristics of prenatal care, complications of pregnancy and childbirth and resolution of pregnancy - number of prenatal consultations, location of prenatal care, type of pregnancy, resolution of pregnancy, preeclampsia, premature labor, placenta previa, premature detachment of the placenta, premature rupture of membranes, gestational diabetes, polyhydramnios, oligodramnios, fetal growth restriction, fetal distress, use of antenatal corticosteroids; Block VI - proximal variables: newborn health conditions and complications up to 28 days of life - gestational age at resolution, gender, birth weight, Apgar $1^{\text {st }}$ and $5^{\text {th }}$ minutes, place of hospitalization, presence of congenital malformation, convulsion, hypothermia, hypoglycemia, necrotizing enterocolitis (NEC) use of $\mathrm{O}_{2}$ by Hood, use of $\mathrm{O}_{2}$ by continuous positive airway pressure (CPAP), use of $\mathrm{O}_{2}$ by mechanical ventilation (MV), central venous access (CVC) with peripheral and central insertion, umbilical catheter, infection, jaundice, use of phototherapy, use of blood products, use of vasoactive drugs, surgery, use of total parenteral nutrition (TPN), resuscitation maneuvers in the delivery room (intubation and cardiac massage).

Univariate analyses (Pearson's chi-square test and Fisher's exact test) were performed between the outcomes and each of the independent variables. Variables with $p \leq 0.20$ were included in the multinomial logistic regression. The regression was done via the stepwise forward method in stages with variables of each of the blocks (distal, intermediate, and proximal). Variables that obtained $p<0.05$ in the multivariate analysis by blocks were included in the final regression model to identify the predictors for the various outcomes. 10

The odds ratio (OR) was calculated with 95\% confidence intervals (CI95\%). Statistical analyses were performed using statistical package SPSS version 24.0 for Windows ${ }^{\circledR}$. The data were compiled using Excel ${ }^{\circledR}$ software (2010), and the results are presented in tables.

The sample power was calculated a posteriori using the program $\mathrm{G} *$ Power 3.1.9.2., reaching $99.6 \%$ power, 11 with the following input parameters: Tail(s) = Two; Odds ratio $=7.05$ (based on the variable with the lowest odds ratio, place of hospitalization); $\operatorname{Pr}(\mathrm{Y}=1 \mid \mathrm{X}=1) \mathrm{H} 0=0.11$ (based on the variable with the lowest odds ratio, place of hospitalization); $\alpha=0.01$; Total sample size $=1092 ; \mathrm{R}^{2}$ other $\mathrm{X}=$ 0.778; $\mathrm{X}$ distribution $=$ Binomial; $\mathrm{X}$ parm $\pi=0.73$.

The study was carried out upon the approval of the Research Ethics Committee (CEP - Portuguese acronym) of Maternity School Assis Chateaubriand
(MEAC-UFC), under number 1,869,528. We also requested opinions with the $\mathrm{CEP}$ for each transfer institution, namely, Hospital and Maternity Doctor ZildaArns Neumann, opinion no. 2,786,308, and General Hospital Waldemar de Alcântara, opinion no. 3,016,236. This study complied with the recommendations of Resolution No. 466/12 of the National Health Council.

\section{Results}

Among the 4,929 births, 392 were near miss newborns. Distribution of NMM is presented as follows: $16.6 \%(65 / 392)$ had congenital malformation, $26 \%(102 / 392)$ had Apgar scores $<7$ in the 5 th minute, $60.5 \%$ (237/392) had weight $<1500 \mathrm{~g}, 61.9 \%$ $(243 / 392)$ had gestational age $<32$ weeks and $66.8 \%$ $(262 / 392)$ had been assisted with mechanical ventilation. Twenty newborns with lethal malformations and/or chromosomal syndromes were excluded, while eight newborns were lost to follow-up. Thus, 364 and 728 newborns were considered as cases and controls, respectively. Among the cases, 267 survived (true near miss newborns), while 97 died during the neonatal period. Moreover, among those who died, $68 \%$ and $32 \%$ had early and late deaths, respectively (Figure 1).

Maternal sociodemographic characteristics that showed no significant difference were education $(p=0.910)$ and marital status $(p=0.440)$. Maternal occupation $(p=0.169)$, race $(p=0.060)$, and origin variable $(p<0.001)$ were selected for the multinomial analysis.

Maternal characteristics and conditions that showed statistical significance were maternal age $(p=0.037)$ and presence of diabetes mellitus ( $p=0.013$ ). Other variables of this level selected for the multinomial analysis include: number of pregnancies $(p=0.150)$, arterial hypertension $(p=0.075)$, smoking $(p=0.145)$, anemia $(p=0.136)$, and urinary infection $(p=0.176)$.

The prevalence of premature and caesarianbirths were $40.7 \%$ and $58.3 \%$, respectively. Table 1 presents the univariate analysis related to the intermediate II variables of hierarchical modeling: prenatal care, and complications of pregnancy, childbirth, and resolution of pregnancy.

All the proximal variables of the hierarchical modeling that concern the health conditions of the newborn and neonatal care showed statistically significant associations with neonatal near miss and death in the univariate analysis (Table 2).

The multinomial analysis of variables that revealed significant results for the three hierarchical 
levels is shown in Table 3. Regarding the distal level, only the origin variable was significantly associated when comparing the control with the near miss groups $(\mathrm{OR}=2.5)$ and with the death groups $(\mathrm{OR}=2.2)$. However, there was no significant association observed between the neonatal near miss group and death.

As for maternal characteristics and conditions, systemic arterial hypertension and age $\leq 18$ years remained significant only in the control and near miss groups, with OR values of 1.6 and 1.7, respectively. Regarding intermediate level II (prenatal care, complications during pregnancy and childbirth, and resolution of pregnancy), the number of prenatal visits and use of antenatal corticosteroids showed significant associations. The number of prenatal visits $\leq 4$ was significant in the three groups. The use of antenatal corticosteroids was associated $(\mathrm{OR}=3.0)$ in the control and near miss groups while no significant association was observed in the control and

Figure 1

Newborns selected in the study sample based on the classification of the final outcome. Maternity-School Assis Chateaubriand-UFC, 2017.

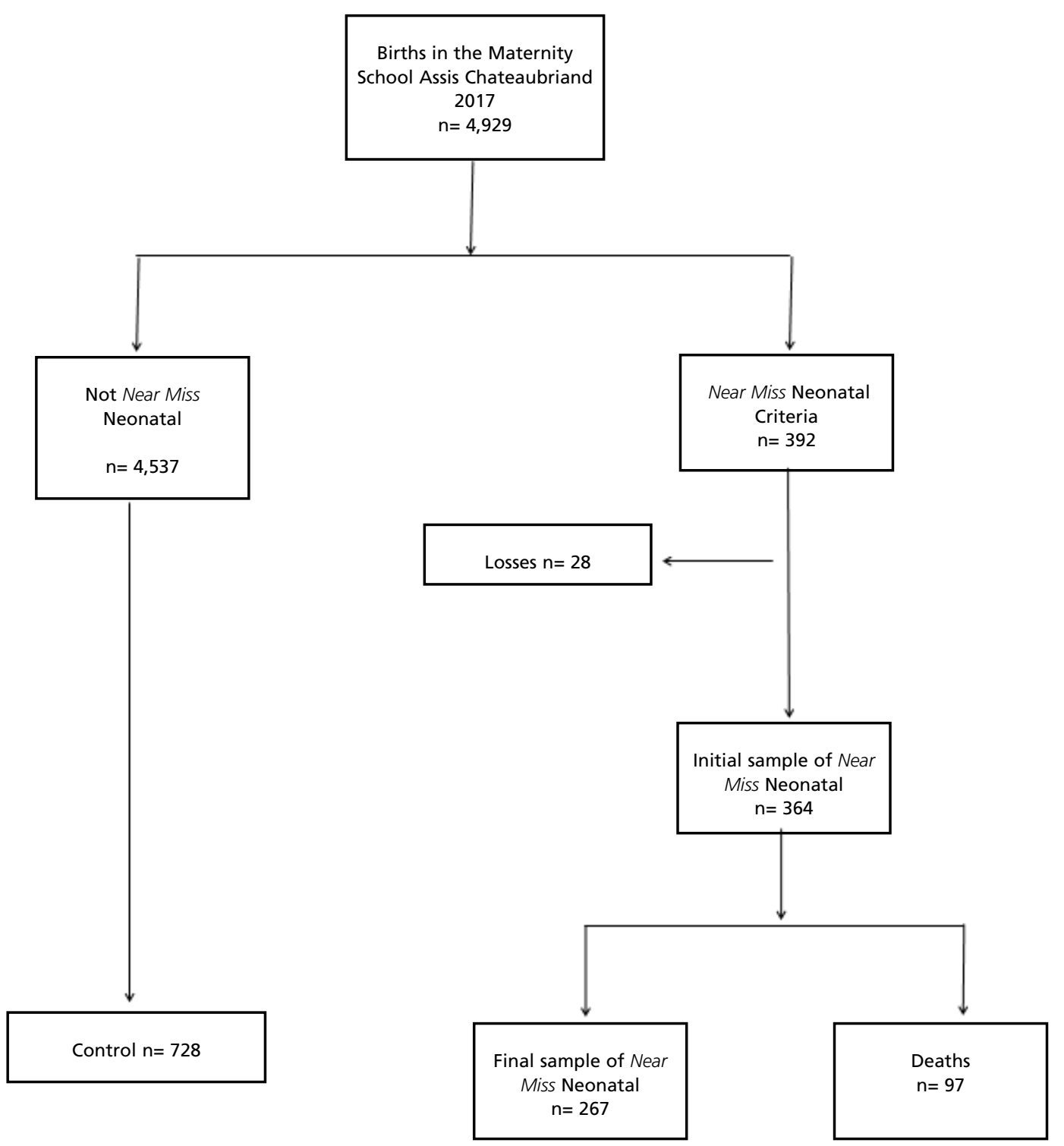


Characteristics of prenatal care, complications during pregnancy and childbirth and pregnancy resolution between controls, neonatal near miss (NNM) and death. Fortaleza-Ceará, 2017.

\begin{tabular}{|c|c|c|c|c|c|c|c|}
\hline Variable & Control & $\%$ & NNM & $\%$ & Death & $\%$ & $p$ \\
\hline Number of prenatal consultations & & & & & & & $<0.001 *$ \\
\hline$\leq 4$ & 94 & 13.5 & 85 & 33.2 & 42 & 47.2 & \\
\hline $5-6$ & 169 & 24.3 & 84 & 32.8 & 25 & 28.1 & \\
\hline$\geq 7$ & 433 & 62.2 & 87 & 34.0 & 22 & 24.7 & \\
\hline Prenatal location & & & & & & & $0.034 *$ \\
\hline Primary attention & 538 & 77.6 & 181 & 70.9 & 60 & 64.5 & \\
\hline Specialized/MEAC & 142 & 20.5 & 69 & 27.1 & 30 & 32.3 & \\
\hline Private clinic & 13 & 1.9 & 5 & 2.0 & 3 & 3.2 & \\
\hline Type of pregnancy & & & & & & & $<0.001 * *$ \\
\hline Singleton & 708 & 93.7 & 212 & 79.4 & 78 & 80.4 & \\
\hline Twin & 20 & 2.7 & 49 & 18.4 & 17 & 17.5 & \\
\hline Triplet & 0 & - & 6 & 2.2 & 2 & 2.1 & \\
\hline Pregnancy resolution & & & & & & & $<0.001 * *$ \\
\hline Vaginal delivery & 329 & 45.2 & 75 & 28.1 & 48 & 49.5 & \\
\hline Cesarean delivery & 396 & 54.4 & 192 & 71.9 & 49 & 50.5 & \\
\hline Forceps childbirth & 3 & 0.4 & 0 & - & 0 & - & \\
\hline Preeclampsia & & & & & & & $<0.001$ * \\
\hline Yes & 164 & 22.5 & 94 & 35.2 & 27 & 27.8 & \\
\hline Premature labor & & & & & & & $<0.001$ * \\
\hline Yes & 141 & 19.4 & 220 & 82.4 & 83 & 85.6 & \\
\hline Placenta previa & & & & & & & 0.051 ** \\
\hline Yes & 2 & 0.3 & 4 & 1.5 & 0 & - & \\
\hline Gestational diabetes & & & & & & & $0.012^{*}$ \\
\hline Yes & 45 & 6.3 & 11 & 4.2 & 12 & 13.0 & \\
\hline Placental abruption & & & & & & & $0.001 *$ \\
\hline Yes & 14 & 1.9 & 30 & 11.2 & 6 & 6.2 & \\
\hline PROM & & & & & & & $<0.001$ * \\
\hline$<18$ hours & 158 & 21.7 & 31 & 11.6 & 17 & 17.7 & \\
\hline$\geq 18$ hours & 60 & 8.2 & 49 & 17.2 & 18 & 18.6 & \\
\hline No & 510 & 70.1 & 190 & 71.2 & 62 & 63.9 & \\
\hline Oligohydramnios & & & & & & & $<0.001^{*}$ \\
\hline Yes & 44 & 6.5 & 29 & 11.6 & 19 & 21.8 & \\
\hline Polyhydramnios & & & & & & & $<0.001 *$ \\
\hline Yes & 11 & 1.6 & 16 & 6.4 & 11 & 12.6 & \\
\hline IUGR & & & & & & & $<0.001^{*}$ \\
\hline Yes & 53 & 7.3 & 60 & 22.5 & 21 & 21.6 & \\
\hline Fetal suffering & & & & & & & $0.013^{*}$ \\
\hline Yes & 83 & 11.4 & 48 & 18.0 & 17 & 17.5 & \\
\hline Use of antenatal corticosteroids & & & & & & & $<0.001$ * \\
\hline Yes & 131 & 18.0 & 198 & 74.2 & 65 & 67.0 & \\
\hline
\end{tabular}

$\mathrm{NMM}=$ neonatal near miss; PROM = premature rupture of the ovular membranes; IUGR = intrauterine growth restriction; MEAC=Maternity School Assis Chateaubriand.* Pearson's chi-square test; ** Fisher's exact test. 
death groups. However, it seems that the use of antenatal corticosteroids has a significant protective association $(\mathrm{OR}=0.4)$ in the near miss and death group. The variables preterm labor, placental abruption, intrauterine growth restriction (IUGR), oligohydramnios, and polyhydramnios also showed statistically significant associations.

Regarding the proximal variables, only the following showed significant associations: gestational age, birth weight, Apgar in the $5^{\text {th }}$ minute, hypothermia, confinement in the intensive care unit (ICU) and semi-intensive care, and use of vasoactive drugs (Table 3).

After adjusting for the three-level hierarchical model of neonatal near miss and death, the variables that remained associated and made up the final model of the multinomial logistic regression are shown in Table 4. All variables were proximal including Apgar in the 5th minute, place of hospitalization, use of central venous access (CVC), and use of vasoactive drugs (Nagelkerke's $\mathrm{R}^{2}$ value $=0.778$, Akaike Information Criterion $($ AIC $)=517$ ).

\section{Discussion}

The definition of the neonatal near miss event is still under discussion. The development of this criterion warrants involvement of a variety of results with various etiologies. In this study, the role of several factors such as sociodemographic determinants, maternal characteristics and conditions, prenatal and delivery assistance, newborn health conditions, and neonatal care on neonatal near miss and deaths were studied. This augments the criteria for life-threatening conditions from the definition of Silva et al. 3

Some of these variables are already recommended by the Latin American Center for Perinatology (CLAP) covering two sets of criteria, namely, pragmatic and management criteria, to identify newborns at high risk for death at birth.

This study has found that neonatal morbidity and mortality among near miss newborns were 54.1 and 2.75 per thousand live births, respectively. These disturbing rates unfortunately reaffirm the need to understand the factors associated with the neonatal near miss event and death, mainly because neonatal near miss morbidity has been proposed as an indicator of healthcare quality. 12 The greater the mortality from near miss cases, the worse the quality of care provided to prevent progression of severe morbidity to fatality

The final model of multinomial regression has shown that distal determinants (i.e. sociodemographic indicators) and intermediate determinants (maternal characteristics or conditions, prenatal care, complications during pregnancy, and childbirth) were not associated with neonatal near miss and death. Proximal determinants, such as health conditions of the newborn and neonatal care, were associated with neonatal near miss and death. Furthermore, the variables that were shown to increase the chance of neonatal near miss and death were: Apgar in the $5^{\text {th }}$ minute, place of hospitalization, use of CVC, and use of vasoactive drugs.

It is worth mentioning that the determination of causality goes through different hierarchical levels, with some of these causal factors being closer than others, in relation to the development of the clinical condition. In the context of neonatal morbidity and mortality, distal determinants or the factors that contribute to the conditions through their impact on other sectors rarely directly affect the outcome. As for the intermediate factors, it is possible that the presence of maternal diseases, inadequate prenatal care, and complications during pregnancy and childbirth may have triggered events that remained associated with neonatal near miss or death. 9

In the literature, sociodemographic indicators have been widely described as risk factors for neonatal morbidity and mortality. A survey involving eight reference hospitals of Recife (northeastern Brazil city) have shown that about $90 \%$ of neonatal near miss cases were associated with low economic classes. 13 Also in northeastern Brazil, a prospective study conducted with pragmatic and management criteria for neonatal near miss in a maternity hospital for women with high-risk pregnancies have also reported that sociodemographic factors did not associate with the outcome. 14 These studies are consistent with the data of this paper. It should be noted that the entire sample of this work came from hospitals with exclusively public services, which are traditionally responsible for the health care of the poorest socioeconomic classes.

In a study on the prevalence and factors associated with neonatal near miss in a municipality in southern Brazil, cesarean delivery doubles the risk of neonatal near miss. ${ }^{15}$ Furthermore, there is evidence that several negative health outcomes, such as neonatal respiratory disease, prematurity, admission to the ICU, and use of mechanical ventilation associated with abdominal delivery. ${ }^{16,17}$ In this study, cesarean section was significantly prevalent $(58.3 \%)$ showing an association in the univariate analysis. This, however, was not associated with the outcome studied in the final model. The high rate of surgical deliveries was justified because the hospitals involved are regional referral hospitals for high- 
Table 2

\begin{tabular}{|c|c|c|c|c|c|c|c|}
\hline Variable & Control & $\%$ & NNM & $\%$ & Death & $\%$ & $p$ \\
\hline Gestational age of resolution (weeks) & & & & & & & $<0.001$ * \\
\hline$<37$ & 146 & 20.1 & 225 & 84.3 & 85 & 87.6 & \\
\hline$\geq 37$ & 582 & 79.9 & 42 & 15.7 & 12 & 12.4 & \\
\hline Gender & & & & & & & $<0.001 *$ \\
\hline Female & 376 & 51.6 & 124 & 46.6 & 40 & 42.6 & \\
\hline Male & 352 & 48.4 & 142 & 53.4 & 54 & 57.4 & \\
\hline Birth weight (grams) & & & & & & & $<0.001^{*}$ \\
\hline$<1750$ & 11 & 1.5 & 188 & 70.4 & 74 & 76.3 & \\
\hline$\geq 1750$ & 717 & 98.5 & 79 & 29.6 & 23 & 23.7 & \\
\hline Apgar score in 1-min & & & & & & & $<0.001^{*}$ \\
\hline$<7$ & 45 & 6.2 & 131 & 49.1 & 77 & 79.4 & \\
\hline$\geq 7$ & 683 & 93.8 & 136 & 50.9 & 20 & 20.6 & \\
\hline Apgar score in 5 -min & & & & & & & $<0.001$ ** \\
\hline$<7$ & 0 & - & 53 & 19.9 & 49 & 50.5 & \\
\hline$\geq 7$ & 728 & 100.0 & 215 & 80.1 & 48 & 49.5 & \\
\hline Place of stay & & & & & & & $<0.001^{*}$ \\
\hline ICU & 37 & 5.1 & 213 & 79.8 & 92 & 94.9 & \\
\hline Semi-intensive & 87 & 11.9 & 32 & 12.0 & 1 & 1.0 & \\
\hline Joint accommodation & 604 & 83.0 & 22 & 8.2 & 4 & 4.1 & \\
\hline Presence of FM & & & & & & & $<0.001 * *$ \\
\hline Yes & 0 & - & 38 & 14.3 & 27 & 2.8 & \\
\hline Infection & & & & & & & $<0.001$ ** \\
\hline Yes & 21 & 2.9 & 154 & 57.7 & 97 & 100.0 & \\
\hline Jaundice & & & & & & & $<0.001^{*}$ \\
\hline Yes & 297 & 40.8 & 239 & 89.5 & 56 & 57.7 & \\
\hline Seizure & & & & & & & $<0.001$ ** \\
\hline Yes & 0 & - & 8 & 3.0 & 1 & 1.0 & \\
\hline Hypothermia & & & & & & & $<0.001 *$ \\
\hline Yes & 68 & 9.3 & 213 & 79.8 & 75 & 78.1 & \\
\hline Hypoglycemia & & & & & & & $<0.001^{*}$ \\
\hline Yes & 111 & 15.2 & 95 & 35.6 & 25 & 26.0 & \\
\hline NEC & & & & & & & $<0.001^{*}$ \\
\hline Yes & 1 & 0.1 & 18 & 6.8 & 7 & 7.2 & \\
\hline $\mathrm{O}_{2}$ by hood & & & & & & & $<0.001 *$ \\
\hline Yes & 122 & 16.8 & 27 & 10.1 & 1 & 1.0 & \\
\hline $\mathrm{O}_{2}$ by CPAP & & & & & & & $<0.001^{*}$ \\
\hline Yes & 23 & 3.2 & 58 & 21.7 & 3 & 3.1 & \\
\hline MV & & & & & & & $<0.001 * *$ \\
\hline Yes & 0 & - & 170 & 63.7 & 92 & 94.8 & \\
\hline \multicolumn{8}{|l|}{ Central venous access (peripheral } \\
\hline and central insertion) & & & & & & & $<0.001 *$ \\
\hline Yes & 8 & 1.1 & 188 & 70.4 & 29 & 29.9 & \\
\hline Use umbilical catheter & & & & & & & $<0.001 *$ \\
\hline Yes & 9 & 1.2 & 199 & 74.5 & 89 & 91.8 & \\
\hline Use of phototherapy & & & & & & & $<0.001$ \\
\hline \multirow[t]{2}{*}{ Yes } & 280 & 38.5 & 235 & 88.0 & 55 & 56.7 & \\
\hline & & & & & & & continue \\
\hline
\end{tabular}

$\mathrm{NNM}=$ neonatal near miss; ICU = intensive care unit; $\mathrm{FM}=$ fetal malformation; NEC = necrotizing enterocolitis; CPAP = continuous positive airway pressure; $M V=$ mechanical ventilation; TPN = total parenteral nutrition; * Pearson's chisquare test; ** Fisher's exact test. 
Health conditions of the newborn and neonatal care between controls NNM and death. Fortaleza-Ceará. 2017.

\begin{tabular}{|c|c|c|c|c|c|c|c|}
\hline Variable & Control & $\%$ & NNM & $\%$ & Death & $\%$ & $p$ \\
\hline Use of blood products & & & & & & & $<0.001$ * \\
\hline Yes & 2 & 0.3 & 68 & 25.5 & 44 & 45.4 & \\
\hline Surgery & & & & & & & $<0.001$ * \\
\hline Yes & 2 & 0.3 & 33 & 12.4 & 17 & 17.5 & \\
\hline Use of TPN & & & & & & & $<0.001$ * \\
\hline Yes & 4 & 0.6 & 190 & 71.2 & 71 & 73.2 & \\
\hline Use of vasoactive drugs & & & & & & & $<0.001 * *$ \\
\hline Yes & 0 & - & 36 & 13.6 & 85 & 87.6 & \\
\hline \multicolumn{8}{|c|}{ Resuscitation maneuvers in } \\
\hline the delivery room & & & & & & & $<0.001 *$ \\
\hline Yes & 1 & 0.1 & 143 & 53.5 & 85 & 87.6 & \\
\hline
\end{tabular}

NNM = neonatal near miss; ICU = intensive care unit; $F M=$ fetal malformation; NEC = necrotizing enterocolitis; $C P A P=$ continuous positive airway pressure; $\mathrm{MV}=$ mechanical ventilation; TPN = total parenteral nutrition; * Pearson's chisquare test; ** Fisher's exact test.

\section{Table 3}

Multinomial analysis of the distal, intermediate and proximal variables associated with the controls NNM and deaths. Fortaleza - Ceará. 2017.

\begin{tabular}{|c|c|c|c|}
\hline & ${ }^{*}$ Control x Near miss & ${ }^{*}$ Control x Death & *Near miss x Death \\
\hline & OR (CI95\%) & OR $(\mathrm{Cl} 95 \%)$ & OR $(\mathrm{Cl} 95 \%)$ \\
\hline \multicolumn{4}{|c|}{ Block I - Distal variables - sociodemographic } \\
\hline Origin - inland & $2.5(1.7-3.5)$ & $2.2(1.3-3.7)$ & $0.9(0.5-1.6)$ \\
\hline \multicolumn{4}{|c|}{$\begin{array}{l}\text { Block II - Intermediate variables I - } \\
\text { maternal characteristics and conditions }\end{array}$} \\
\hline SAH & $1.6(1.0-2.7)$ & $1.8(0.9-3.6)$ & $1.1(0.5-2.3)$ \\
\hline Age range $\leq 18$ years & $1.7(1.1-2.5)$ & $1.0(0.5-2.0)$ & $0.6(0.3-1.3)$ \\
\hline
\end{tabular}

Block III / IV / V - Intermediate variables II prenatal care, complications during pregnancy and childbirth and resolution of pregnancy Number of prenatal consultations $\leq 4$

$\begin{array}{cc}2.5(1.5-4.0) & 5.3(2.7-10.4) \\ 3.0(1.8-5.1) & 1.3(0.7-2.6) \\ 7.3(4.2-12.6) & 13.5(5.9-30.5) \\ 5.0(2.2-11.6) & 2.1(0.6-6.9) \\ 3.6(2.1-6.1) & 3.3(1.7-6.7) \\ 0.78(0.41-1.46) & 2.07(0.99-4.33) \\ 7.1(2.8-18.3) & 22.3(7.8-64.2)\end{array}$
Use of antenatal corticosteroids Premature labor

Placental abruption

Fetal growth restriction

Oligohydramnios

Polyhydramnios

Block VI - Proximal variables - health conditions of the newborn and neonatal care Gestational age (weeks)

Birth weight (grams)

Apgar in the $5^{\text {th }}$ minute $<7$

Hypothermia

Place of stay - NICU

Place of stay - semi-intensive

$$
\begin{gathered}
20.4(1.6-250.0) \\
10.9(3.1-3.8) \\
* * \\
8.0(2.1-30.6) \\
30.7(5.6-166.4) \\
3.6(0.6-22.8) \\
8.9(1.8-44.6) \\
* *
\end{gathered}
$$$$
1.7(0.7-333.3)
$$$$
0.8(0.1-6.7)
$$$$
32.3(4.9-200.0)
$$$$
\text { ** }
$$$$
2.9(0.7-1.3)
$$$$
5.2(0.9-29.6)
$$$$
7.1(2.4-20.8)
$$$$
53.9(3.5-823.9)
$$$$
0.6(0.2-2.0)
$$$$
3.0(0.1-109.1)
$$$$
1.8(0.2-15.2)
$$

Use of CVC (peripheral and central insertion)

$0.7(0.1-4.5)$

$0.9(0.1-18.9)$

Use of vasoactive drugs$$
\text { ** }
$$$$
0.1(0.1-0.2)
$$

$14.0(5.3-37.0)$

$\mathrm{NNM}=$ neonatal near miss; SAH = Systemic Arterial Hypertension; NICU = neonatal intensive care unit; CVC = central venous access; $\mathrm{SAH}=$ systemic arterial hypertension; $\mathrm{CI} 95 \%=95 \%$ confidence interval; OR $=$ odds ratio. * Reference between groups; $* *$ Impossible to calculate because of the quasi separation. ${ }^{10}$ 
The final hierarchical logistic regression model of the determinants associated with neonatal near miss and death. Fortaleza - Ceará. 2017.

\begin{tabular}{lccc}
\hline Variable & $*$ Control x Near miss & $*$ Controle x Death & $*$ Near miss x Death \\
\cline { 2 - 4 } & OR (Cl95\%) & OR (Cl95\%) & OR (Cl95\%) \\
\hline Apgar score in 5-min< & $* *$ & $* *$ & $4.1(1.6-10.6)$ \\
Place of stay & & & \\
NICU & $35.6(16.7-75.9)$ & $100.4(18.8-537.0)$ & $2.5(0.5-12.8)$ \\
semi-intensive & $7.1(2.9-16.9)$ & $5.1(0.4-69.9)$ & $0.7(0.1-9.9)$ \\
Use of CVC (peripheral and central insertion) & $74.8(29.4-190.4)$ & $12.7(3.7-43.2)$ & $0.2(0.1-0.4)$ \\
Use of vasoactive drugs & $* *$ & $* *$ & $42.2(17.1-104.5)$ \\
& & & \\
\hline
\end{tabular}

$\mathrm{NICU}=$ neonatal intensive care unit; $\mathrm{CVC}=$ central venous access; $\mathrm{CI} 195 \%=95 \%$ confidence interval; OR= odds ratio

* Reference between groups; ** Impossible to calculate because of the quasi separation. 10

risk maternal and neonatal care.

Proper prenatal care has been shown to be one of the most relevant factors for preventing unfavorable outcomes such as low birth weight, prematurity, IUGR, and neonatal deaths. The quality of care provided during prenatal period can cause a $10-20 \%$ reduction in all neonatal deaths. 18 Studies have shown that unfavorable perinatal results were due to delayed, insufficient, and inaccessible prenatal care. 1,19

Since 1990, Brazil has advanced the coverage of prenatal care to over $90 \%$ in all of the regions in the country. The scope was wide, reaching women with different demographic, social, and reproductive characteristics. 20

In the present study, $52.1 \%$ of pregnant women had 7 or more consultations. However, multinomial analysis has shown that prenatal consultations $\leq 4$ were associated with neonatal near miss and death. This emphasizes the importance of prenatal care in the prevention of unfavorable health outcomes.

The reduction of neonatal morbidity and mortality is difficult to attain due to its close and complex relationship with social, biological, and health care determinants. Health care determinants, especially those practiced in the hospital setting where almost all births occur in Brazil, included obsolete practices, medicalization of childbirth, availability of beds, overcrowding, deficiency in material resources (equipment and supplies), hospital complexity, and lack of professional training. 21,22

The data from this study have pointed out that the chances for neonatal near miss and death are related, especially, to the newborn's conditions and neonatal care. Studies show that the first two days and first week of life are responsible for more than $50 \%$ and $75 \%$ of neonatal deaths, respectively. These deaths are often the result of asphyxia at birth, prematurity, sepsis, and congenital malformation. 23 In this study, the proportion of deaths that had occurred in the first week of life was $68 \%$ (66/97), which is close to the expected $75 \%$ from other studies. These results have emphasized that interventions should be focused on the period of delivery and shortly after birth.

Although WHO recommendations for postnatal care already exist for at least 24 hours after birth, a new concept involving the first hour of life (golden hour) has recently been introduced in the field of neonatology. It is estimated that if implemented worldwide, these recommendations can reduce neonatal deaths by up to one million. 24,25 These guidelines involve the use of evidence-based interventions aimed at minimizing neonatal complications to yield the best neonatal outcomes. 26

In the final model of the study, (1) Apgar in the 5 th minute, (2) place of hospitalization, (3) use of $\mathrm{CVC}$, and (4) use of vasoactive drugs were significantly associated to near miss and death.

Apgar score $(<7)$ in the $5^{\text {th }}$ minute of life showed a statistically significant association (OR of 4.12) when comparing the near miss and death groups. This association has been consistently verified in the literature. Poor birth conditions related to low Apgar values in the $5^{\text {th }}$ minute is also related to several unfavorable situations to the newborn, such as the need for intubation, the use of mechanical ventilation, and admission to the ICU. Neonates with low Apgar scores are 15 times more likely to die than those with normal Apgar. ${ }^{27}$

The place of hospitalization is also an important predictor of clinical outcome. Compared to controls, neonates confined in the ICU were 35.6 and 100.4 times more likely to become cases of near miss and death, respectively. Neonatal ICUs are designated 
spaces equipped with advanced and highly complex life support technologies to provide clinical management in newborns with serious medical conditions. ${ }^{28}$ Various invasive procedures crucial in high-risk patients contributes to an increased risk of infections. 29

The use of CVC and vasoactive drugs were the main predictors of the most unfavorable outcomes in this study. Neonates with central venous access were 74.8 times and 12.7 times more prevalent in the near miss group and death group, respectively, than in the control group. However, in the near miss group, $\mathrm{CVC}$ has been shown to be protective against death. Neonates using vasoactive drugs are 42.2 times more likely to die in the neonatal near miss group.

These findings corroborate with this study, in which the use of central venous catheter increased the chance of neonatal near miss and death by $74.8 \%$ and $12.7 \%$, respectively, when compared to controls. Among the newborns in this study, $31.3 \%$ were hospitalized in the NICU, $24 \%$ have used MV, $32.3 \%$ had hypothermia, $24.9 \%$ had infection, $20.6 \%$ have used $\mathrm{CVC}$, and $11.2 \%$ have used vasoactive drugs. Among the newborns that have used vasoactive drugs, $87.6 \%$ (85) died.

This was the first study to be developed in Ceará with the objective of evaluating neonatal near miss, in an attempt to estimate the overall scenario in the entire state. Thus, the findings reflect positive and negative points regarding preventive and assistive care in the maternal and pediatric context. This was a study involving the prospective selection of cases and controls covering all deliveries that occurred daily in a year, in a tertiary care maternity.

As for improving neonatal care, the Ministry of Health developed the QualiNEO Strategy in 2019.30 This strategy aims to reduce neonatal mortality rates and provide neonatal and maternal care in the North and Northeast regions. Ceará, the setting of the study, is chosen as the matrix state because it has a reference center for good practices in childbirth and birth assistance recommended by Rede Cegonha (Stork Network). This may direct more appropriate behaviors and agreements by the assistance and management teams.

Despite its comprehensive methodology, some possible limitations of this study must be addressed in the future. Although the participant selection was carried out prospectively, the data collection occurred retrospectively. The medical records were reviewed after 28 days of inclusion in the study in order to check the selection and inclusion criteria, and search for data on neonatal outcomes and morbidities. This implies that there was a secondary source of data subject to information bias. However, it is worth mentioning that other sources of records, such as birth and death declarations, and the pregnant woman's card, were collected in addition to the medical records.

Another issue to be considered is that the study of neonatal near miss was derived from a tertiary maternity hospital for women with high-risk pregnancies. This limits the generalizability of its results to medium - and low-complexity pregnancies. We can highlight once again that the study contemplated a care reference scenario for other adjacent locations, allowing better understanding of the expected result for this care profile. In this way, the results can be extrapolated to several other maternity hospitals in Brazil and other countries including maternalclinical characteristics, socioeconomic profiles and care networks.

The third limitation of this study is that the sample originated from a reference maternity hospital with high complexity care. With the possibility of identifying more cases of neonatal near miss in relation to other maternity hospitals, selection bias might have been committed. However, this might be considered an advantage because the high number of selected cases facilitated a more representative statistical analysis.

The prediction variables associated with neonatal near miss and death point, especially, to the so-called proximal variables related to the health conditions of the newborn and neonatal care. However, the importance of distal and intermediate factors has long been understood, forming a comprehensive chain of causalities. The homogeneity of the population of a lower socioeconomic level may have impaired the analysis of these more distal variables in the studied outcomes.

This study stresses the importance of actions to reduce inequities, improve the educational conditions of the population, provide timely high-quality access to prenatal care, and build a referral network to immediately assist neonatal and maternal needs at birth and post-birth.

\section{Author's contribution}

Carvalho OMC and Carvalho FHC designed the study, interpretation of the data. Carvalho OMC, Xavier ATO and Gouveia involved in data collection. VianaJr AB and Carvalho FHC performed the data analysis. Carvalho OMC and Lopes FNB wrote the manuscript. Carvalho OMC, Augusto MCC and Lopes FNB critically edited the manuscript. 
Carvalho OMC, Augusto MCC and Lopes FNB finalized the manuscript. All authors approved the final version of the manuscript.

\section{References}

1. Pileggi C, Souza JP, Cecatti JG, Faúndes A. Neonatal near miss approach in the 2005 WHO Global SurveyBrazil. J Pediatr. (Rio J). 2010; 86 (1): 21-6.

2. Avenant T. Neonatal near miss: a measure of the quality of obstetric care. Best Pract Res Clin Obstet Gynaecol. 2009; 23 (3): 369-74.

3. Silva AAM, Leite AJM, Lamy ZC, Moreira MEL, Gurge RQ, Cunha AJLA, Leal MC. Neonatal near miss in the Birth in Brazil survey. Cad Saúde Pública (Rio J). 2014; 30 (Suppl1): S182-91.

4. United Nations Children's Fund. Levels \& Trends in Child Mortality: Report 2017 Estimates Developed by the UN Inter-agency Group for Child Mortality Estimation United Nations Child Mortality Report 2017. New York, 2017. [acess on 5 set 2018]. Available from: https://www.unicef.org/publications/files/Child_Mortality Report_2017.pdf.

5. Brazil. Ministry of Health.Datasus. Mortality information system,2017.[acess $10 \mathrm{dez}$ 2018]. Available from: $<$ http://datasus.saude.gov.br/informacoes-de-saude/tabnet>

6. United Nations Children's Fund. Levels \& trends in child mortality: report 2014. New York: UNICEF; 2014. [acess on 20 mar 2016]. Available from: http://www.unicef.org/media/files/Levels_and_Trends_in Child_Mortality_2014.pdf.

7. Kale PL, Silva KS, Saraceni V, Coeli CM, Torres TZG, Vieira FMDSB, Rocha NM, Fonseca SC. Life-threatening conditions at birth: an analysis of causes of death and survival estimate for under-five children in live birth cohorts. Cad Saúde Pública (Rio J). 2019; 35 (7): e00186418.

8. Chalfun G, Mello RR, Dutra MVP, Andreozzi VL, Silva KS. Risk factors for respiratory morbidity at 12 to 36 months in very low birth weight premature infants previously admitted to a public neonatal intensive care unit. Cad Saúde Pública. 2009; 25 (6): 1399-408.

9. Lima S, Carvalho ML, Vasconcelos AGG. Proposal for a hierarchical framework applied to investigation of risk factors for neonatal mortality. Cad Saúde Pública. 2008; 24 (8): 1910-6

10. Garson GD. LogisticRegression: Binary\&Multinomial: Edition 2016. Asheboro (USA): StatisticalPublishing Associates; 2016.

11. Cooper JA, Garson GD. Power Analysis: Edition 206 Asheboro (USA): Statistical Publishing Associates; 2016.

12. Say L. Neonatal near miss: a potentially useful approach to assess quality of newborn care. J Pediatr (Rio J). 2010; 86 (1): $1-2$

13. Brasil DRPA, Vilela MBR, França KEX, Sarinho SW. Neonatal morbidity near miss in tertiary hospitals in a capital of northeast Brazil. Rev Paul Pediatr. 2019; 37 (3): 275-82.

14. Lima THB, Katz SB, Amorim MM. Neonatal near miss determinants at a maternity hospital for high-risk pregnancy in Northeastern Brazil: a prospective study. BMC Pregnancy Childbirth. 2018; 18 (1): 401.

15. Silva GA, AS, Rosa KA, Saguier ESF, Henning E, Mucha F, Franco SC. A populational based study on the prevalence of neonatal near miss in a city located in the South of Brazil: prevalence and associated factors. Rev Bras Saúde Mater Infant. 2017; 17 (1): 159-67.

16. Domingues RMSM, Dias MAB, Schilithz AOC, Leal MC. Factors associated with maternal near miss in childbirth and the postpartum period: findings from the birth in Brazil National Survey, 2011 - 2012. Reprod Health. 2016; 13 (Suppl. 3): 115.

17. Signore C, Klebanorff M. Neonatal Morbidity and mortality after elective cesarian delivery. Clin Perinatol. 2008; 35 (2): 361-71.

18. Kassar Samir B, Melo AMC, Coutinho SB, Lima MC, Lira PIC. Determinants of neonatal death with emphasis on health care during pregnancy, childbirth and reproductive history. J Pediatr (Rio J.). 2013; 89 (3): 269-77.

19. Nunes JT, Gomes KRO, Rodrigues MTP, Mascarenhas MDM. Quality of prenatal care in Brazil: review of published papers from 2005 to 2015. Cad Saúde Coletiva. 2016; 24 (2): 252-61.

20. Viellas EF, Domingues RMSM, Dias MAB, Gama SGN, Theme Filha MM, Costa JV, Bastos MH, Leal MC. Prenatal care in Brazil. Cad Saúde Pública. 2014; 30 (Supl. 1): S85S100.

21. Magluta C, Noronha MF, Gomes MAM, Aquino LA, Alves CA, Silva RS. The structure of Brazilian National Health Service Maternity Hospitals in Rio de Janeiro: the challenge of providing quality health care. Rev Bras Saúde Matern Infant. 2009; 9 (3): 319-29.

22. Gaiva MAM, Rosa MKO, Barbosa MARRS, Bittencourt RM, Souza SS. Structural evaluation of hospital institutions that give birth assistance in Cuiabá, MT. Cogitare Enferm. 2010; 15 (1): 55-62.

23. Carlo WA, Travers CP. Maternal and neonatal mortality: time to act. J Pediatr (Rio J.). 2016; 92 (6): 543-5.

24. WHO (World Health Organization). WHO recommendations on postnatal care of the mother and newborn. Geneva; 2013. Available from: $<$ https://apps.who.int/iris/bitstream/handle/10665/97603/97 89241506649_eng.pdf.>.acess on: 30 mar. 2016.

25. Little G, Niermeyer S, Singhal N, Lawn J, Keenan W. Neonatal resuscitation: a global challenge. Pediatrics. 2010; 126 (5): e1259-60. 
26. Sharma D. Golden hour of neonatal life: need of the hour Matern Health Neonatol Perinatol. 2017; 3: 16.

27. Lansky S, Friche AAL, Silva AAM, Campos D, Bittencourt SDA, Carvalho ML, Frias PG, Cavalcante RS, Cunha AJLA. Birth in Brazil survey: neonatal mortality, pregnancy and childbirth quality of care. Cad Saúde Pública.2014; 30: S192-S207.

28. Silva LJ, Silva LR, Christoffel MM. Technology and humanization of the neonatal intensive care unit: reflections in the contex of the health-illness process. RevEsc Enferm USP. 2009; 43 (3): 684-9.
29. Dessì A, Pravettoni C, Ottonello G, Birocchi F, Cioglia F, Fanos V. Neonatal Sepsis. J Pediatr Neonatol Individualized Med. 2014, 3(2): e030273.

30. Brazil. Ministry of Health. Department of Health Care. Department of Programmatic and Strategic Actions. Quali Neo Strategy. Brasília, 2017. Available from: $<$ http://portalms.saude.gov.br/saude-para-voce/saude-dacrianca/pre-natal-e-parto/estrategia-qualineo $>$.

Received on October 8, 2019

Final version presented on April 8, 2020

Approved on May 20, 2020 